\title{
Factors influencing the Web-based autonomous learning ability of Chinese Vocational College Students: An investigation in Guangdong Province
}

\author{
YANG Wei-jie \\ School of Information \\ Guangdong Teachers College of Foreign Language and Arts \\ Guangzhou, China \\ yangwj@gtcfla.net
}

\author{
DU Fang-fang \\ School of information engineering \\ Guangdong Pharmaceutical University \\ Guangzhou, China \\ dufangfang119@126.com
}

\author{
HUANG Shi-lin \\ School of Information \\ Guangdong Teachers College of Foreign Language and Arts Guangzhou, China
}

\begin{abstract}
This study carried out an investigation of students from 25 vocational colleges $N=6474$ ) in Guangdong province of China, analyzed the status and level of students' Web-based autonomous learning ability, mainly focused on 9 main factors included: Information processing ability, Intrinsic learning motivation, Learning strategies, Environmental factors, Learning meaning, Learning control, Learning anxiety, Self-efficacy and Learning management. The results indicated that the students' gender, grade and type of college (public or private) were effective factors influenced college students' Web-based autonomous learning ability. The result showed that boys were better adapted to Web-based autonomous learning than girls; Students' information processing capacity was continually grown while the students' intrinsic learning motivation of Web-based autonomous learning was decreased gradually in 3 Years. The Web-based autonomous learning ability of students in public colleges was superior to those in private colleges. The data showed that inside the environmental factors, compared with devices \& tools, network access conditions and online learning resources, the teacher's support is insufficient. Correlation analysis demonstrated that four aspects of exterior environmental factors were positively related to the inner factors of learners. The author provided some suggestions for cultivating students' Web-based autonomous learning ability.
\end{abstract}

Keywords-vocational college students; Web-based autonomous learning; ability; investigation;influencing factors

\section{INTRODUCTION}

With the rapid development of information technology and the network infrastructure, multimedia technology and network technology have been widely used in higher vocational education in China. The era of "Internet + Education" is coming. In higher vocational colleges, with the continually construction of Web-based teaching platforms and onlinecourses, the web-based learning resources including video courses, MOOCs were widely used by teachers and students , different web-based learning methods such as blended-learning, mobile learning, flipped-classroom were accepted by students. At present, vocational college students nearly accounted for about half of total students in China. Statistics data showed that in 2013, Guangdong province have 687.6 thousands college students, which accounted for $40.2 \%$ of the total number of full-time students in the universities and colleges. In 2013, the newly enrolled college students were 246 thousands, accounting for $46.8 \%$ of full-time students newly enrolled that year in Guangdong ${ }^{[1]}$. With such a large number of higher vocational students, improving their Web-based autonomous learning ability was of great significance for promoting the overall quality of higher vocational education in China.

\section{WEB-BASED AUTONOMOUS LEARNING ABILITY}

The general meaning of Web-based autonomous learning refers to a learning way that teachers and students depend on the learning support service system in the quasi-discrete state, and take individual autonomous learning as the mainly learning form, teachers and students communicate by network and benefit from the two-way communication ${ }^{[2]}$. It's a learning way depended on the learning support service system provided by the Internet, the learners can autonomously select cognitive tools, determine their learning goals and learning contents, and realize the construction of meaningful knowledge through the interactive process of inquiry. Zhai Xuge believes that the network environmental factors (communication assistance, learning conditions and online learning resources) and individual factors (self-efficacy, goal setting, will level, learning strategies and information processing ability) influence the effect of Web-based autonomous learning ${ }^{[3]}$. $\mathrm{Li}$ Xingrong, Guo Hongsheng, et al. found that learning motivation, network factors, teacher factors and personal factors are the effective factors that affect the effect of Webbased autonomous learning of college students ${ }^{[4]}$.

The author found that related research about the large-scale investigation and analysis of the factors affecting the level of 
self-regulated learning ability and self-regulated learning ability of higher vocational students in China results was relatively rare. In this study, the author carried out a large-scale investigation in Guangdong province so as to research about the vocational college students' Web-based autonomous ability status and find out the effective factors influencing the ability.

\section{METHODOLOGY}

\section{A. Research tools}

The author designed a questionnaire based on the questionnaire 'Investigation and research questionnaire of College Students' Autonomous Learning' designed by $\mathrm{Li}$ Cheng-xin in 2009 ${ }^{[5]}$ and 'Questionnaire of influencing factors of College Students' Autonomous Learning' designed by Yi Ya-nan in $2012^{[6]}$. The questionnaire composed of student's background information and night factors effecting the ability including: Information processing capability (IPC), Intrinsic learning motivation (ILM), Learning strategies (LS), Environmental factors(EF), Learning meaning (LM), learning control (LC), Learning anxiety (LA), Self-efficacy (SE), Learning management (LMA). The items in the questionnaire used the Likert 5 level response model, scoring from "very consistent", "consistent", "general (difficult to determine)", "not consistent" to "very inconsistent", recorded as 5 to 1 points.

The Factor "Information processing ability" referred to evaluate the information processing ability of students who use computers to develop Web-based autonomous learning. The Factor "Intrinsic learning motivation" referred to the motivation level of online learner. The Factors "Learning strategies" referred to general strategies for conducting web learning. The Factor "Environmental factor" referred the student's equipment and devices, network access conditions, availability of learning resources and teachers' support for learners. The Factor "Learning meaning" referred to students' understanding of the significance of Web-based autonomous learning. The factor "Learning control" referred to the learner's self-control in web-based learning. The factor "Learning anxiety" referred to the anxiety of the learners based on the Internet. The factor "Self-efficacy" referred to students' selfefficacy of Web-based autonomous learning. The factor "Learning management" referred to the learning time management and goal management ability in Web-based autonomous learning.

\section{B. Investigation procedure}

The author firstly selected 100 students in Guangdong Teachers College of Foreign Language and Arts to make a pretest, then improved the structure of the questionnaire according to the statistical internal consistency coefficient. The formal survey was conducted through the paper questionnaire and online survey from March to September in 2016, and a total of 25 vocational colleges were investigated in Guangdong. The colleges included Shenzhen Polytechnic, Shunde Polytechnic, Guangdong Communication Polytechnic etc. 7000 copies of the questionnaire were issued, and finally 6685 questionnaires were received, 6474 valid of them, and the effective recovery rate was $92.48 \%$. The valid questionnaires were coded with Microsoft Excel, and then imported into the SPSS 20 software for data analysis.

\section{Sample distribution}

The samples' grade distribution was freshman students accounted for $60.1 \%$, sophomore accounted for $30.5 \%$, junior students accounted for 9.4\%; The samples' gender distribution was boys accounted for $49.6 \%$, girls accounted for $50.4 \%$; The samples' learning Length distribution was 2 Years accounted for $16.9 \%, 3$ Years accounted for $83.1 \%$; The samples' college type distribution was public college accounted for $76.8 \%$,private college accounted for 23.2\%; the College entrance examination types included 3 types, the distribution was universities entrance examination accounted for $70.1 \%$, independent enrollment accounted for $15 \%$, higher vocational college entrance examination accounted for $14.9 \%$.

\section{Questionnaire reliability}

The Reliability Statistics revealed that the internal consistency coefficient of questionnaire was high (Cronbach's Alpha= 0.893).

\section{RESULT}

\section{A. The total average of the vocational students' Web-based} autonomous learning abilities in Guangdong

As demonstrated in Table I, the factors' total average mean ranking of the vocational college students' Web-based autonomous learning abilities in Guangdong was $\mathrm{LM}>\mathrm{EF}>\mathrm{SE}>\mathrm{ILM}>\mathrm{LS}>\mathrm{LMA}>\mathrm{IPC}>\mathrm{LA}>\mathrm{LC}$, in which LA's mean and LC's mean were less than 3.5, LC was the lowest.The total centesimal average score of the whole ablilty was 70.22. Among them, the factor LC (mean=3.0935) was lowest, indicating that students thought that their learning control ability was the in the lowest level and needed to be enhanced.

TABLE I. THE TOTAL AVERAGE OF FACTORS

\begin{tabular}{|l|c|c|c|c|c|}
\hline Factor & $\mathbf{N}$ & Mean & SD & Mark & Order \\
\hline IPC & 6398 & 3.5168 & .64979 & 70.336 & 7 \\
\hline ILM & 6431 & 3.5871 & .71033 & 71.742 & 4 \\
\hline LS & 6341 & 3.5712 & .61111 & 71.424 & 5 \\
\hline EF & 6398 & 3.6168 & .63517 & 72.336 & 2 \\
\hline LM & 6350 & 3.6228 & .72716 & 72.456 & 1 \\
\hline LC & 6431 & 3.0935 & .69204 & 61.87 & 9 \\
\hline LA & 6417 & 3.4666 & .84784 & 69.332 & 8 \\
\hline SE & 6399 & 3.5907 & .68858 & 71.814 & 3 \\
\hline LMA & 6388 & 3.5362 & .78161 & 70.724 & 6 \\
\hline
\end{tabular}

\section{B. The gender differences}

As demonstrated in Table II, the one-way ANOVA analysis result showed that, the gender differences of factors including ILM(Sig=.037), LS(Sig=.000), EF (Sig=.003), LC (Sig=.006), LA (Sig=.000), SE(Sig=.017), LMA(Sig=.000) were significant $(\mathrm{p}<0.05)$, while the gender differences of factors IPC(Sig=.775) and LM(Sig=.072) were no significant. Overall, except for factor intrinsic learning motivation, the other 
factors' score of boys were all higher than those of girls. On the whole, although girls' intrinsic learning motivation level was higher than boys, boys were better adapted to Web-based autonomous learning than girls, and girls should be given more supports when they participated in online learning.

TABLE II. THE GENDER DIFFERENCES OF FACTORS

\begin{tabular}{|c|c|c|c|c|c|c|}
\hline \multicolumn{2}{|c|}{ Factor } & $\mathbf{N}$ & Mean & SD & $\mathbf{F}$ & Sig \\
\hline \multirow{2}{*}{ IPC } & Boy & 3164 & 3.5193 & 0.63969 & \multirow{2}{*}{.082} & \multirow{2}{*}{.775} \\
\hline & Girl & 3213 & 3.5146 & 0.65924 & & \\
\hline \multirow{2}{*}{ ILM } & Boy & 3184 & 3.5687 & 0.67729 & \multirow{2}{*}{4.358} & \multirow[t]{2}{*}{.037} \\
\hline & Girl & 3226 & 3.6057 & 0.74093 & & \\
\hline \multirow{2}{*}{ LS } & Boy & 3137 & 3.6101 & 0.62642 & \multirow{2}{*}{25.287} & \multirow{2}{*}{.000} \\
\hline & Girl & 3183 & 3.533 & 0.59249 & & \\
\hline \multirow{2}{*}{$\mathrm{EF}$} & Boy & 3173 & 3.6403 & 0.65225 & \multirow{2}{*}{8.571} & \multirow[t]{2}{*}{.003} \\
\hline & Girl & 3204 & 3.5938 & 0.61677 & & \\
\hline \multirow{2}{*}{ LM } & Boy & 3144 & 3.6397 & 0.73769 & \multirow{2}{*}{3.235} & \multirow[t]{2}{*}{.072} \\
\hline & Girl & 3188 & 3.6069 & 0.7168 & & \\
\hline \multirow{2}{*}{ LC } & Boy & 3183 & 3.1178 & 0.65131 & \multirow{2}{*}{7.701} & \multirow[t]{2}{*}{.006} \\
\hline & Girl & 3228 & 3.0699 & 0.72954 & & \\
\hline \multirow{2}{*}{ LA } & Boy & 3175 & 3.5046 & 0.92592 & \multirow{2}{*}{12.453} & \multirow[t]{2}{*}{.000} \\
\hline & Girl & 3221 & 3.4298 & 0.76077 & & \\
\hline \multirow{2}{*}{ SE } & Boy & 3169 & 3.6117 & 0.70025 & \multirow{2}{*}{5.709} & \multirow[t]{2}{*}{.017} \\
\hline & Girl & 3209 & 3.5705 & 0.67592 & & \\
\hline \multirow{2}{*}{ LMA } & Boy & 3159 & 3.5788 & 0.78789 & \multirow{2}{*}{18.367} & \multirow[t]{2}{*}{.000} \\
\hline & Girl & 3208 & 3.495 & 0.77252 & & \\
\hline
\end{tabular}

\section{The grade differences}

As demonstrated in Table III, the one-way ANOVA analysis result showed that, the grade differences of factors including IPC(Sig=.004), $\mathrm{LS}(\mathrm{Sig}=.000), \quad \mathrm{EF}(\mathrm{Sig}=.000)$, LM(Sig=.000), LC(Sig=.012), LA(Sig=.000), SE(Sig=.002), LMA(Sig=.000) were significant, while the grade differences of factor ILM(Sig=.130) was no significant. The grade difference of factor IPC was significant and the order of scores was grade $1<$ grade $2<$ grade 3 , it indicated that the vocational college students' information processing capacity was continually grown during 3 years. At the same time, even though the grade difference of factor ILM was not so significant, but the score was continually declined, it indicated that the students' Intrinsic learning motivation of Web-based autonomous learning was decreased gradually during 3 years. The scores of factors included LS, EF, LM, LC, LA, SE, LMA all showed rise first and then decrease slightly, it revealed that there was a peak in grade 2. After having done in-depth interviews with students, the author fund that this change was concerned about the whole learning length in the college, the students have more basic major courses and general courses in grade 1 , their capacities of ICT grown quickly in grade 1.And then more specialized courses opened for them in the grade 2, in this year, their teachers in specialized courses were also more inclined to use Web-based courses, e-learning platforms and online-resources to teach. In the grade 3, when there were less major course than grade 2 and the Juniors student would leave their college during their internship. The change of these factors indicated that it was most important to offer supports for student in the grade 2 .
TABLE III. THE GENDER DIFFERENCES OF FACTORS

\begin{tabular}{|c|c|c|c|c|c|c|}
\hline \multicolumn{2}{|c|}{ Factor } & $\mathbf{N}$ & Mean & SD & $\mathbf{F}$ & Sig. \\
\hline \multirow{3}{*}{ IPC } & Grade 1 & 3781 & 3.4994 & 0.63058 & \multirow{3}{*}{5.503} & \multirow{3}{*}{.004} \\
\hline & Grade 2 & 1926 & 3.5447 & 0.64508 & & \\
\hline & Grade 3 & 599 & 3.576 & 0.77364 & & \\
\hline \multirow{3}{*}{ ILM } & Grade 1 & 3809 & 3.6056 & 0.67246 & \multirow{3}{*}{2.042} & \multirow{3}{*}{.130} \\
\hline & Grade 2 & 1934 & 3.5691 & 0.72071 & & \\
\hline & Grade 3 & 596 & 3.5677 & 0.88903 & & \\
\hline \multirow{3}{*}{ LS } & Grade 1 & 3747 & 3.5243 & 0.62114 & \multirow{3}{*}{33.926} & \multirow{3}{*}{.000} \\
\hline & Grade 2 & 1913 & 3.6616 & 0.59544 & & \\
\hline & Grade 3 & 591 & 3.6193 & 0.5709 & & \\
\hline \multirow{3}{*}{$\mathrm{EF}$} & Grade 1 & 3788 & 3.5888 & 0.65578 & \multirow{3}{*}{16.062} & \multirow{3}{*}{.000} \\
\hline & Grade 2 & 1921 & 3.6877 & 0.60061 & & \\
\hline & Grade 3 & 597 & 3.5934 & 0.59621 & & \\
\hline \multirow{3}{*}{ LM } & Grade 1 & 3761 & 3.6092 & 0.73228 & \multirow{3}{*}{10.366} & \multirow{3}{*}{.000} \\
\hline & Grade 2 & 1903 & 3.6844 & 0.72112 & & \\
\hline & Grade 3 & 597 & 3.5505 & 0.70467 & & \\
\hline \multirow{3}{*}{ LC } & Grade 1 & 3809 & 3.0927 & 0.72222 & \multirow{3}{*}{4.423} & \multirow{3}{*}{.012} \\
\hline & Grade 2 & 1937 & 3.1226 & 0.65816 & & \\
\hline & Grade 3 & 595 & 3.0269 & 0.6135 & & \\
\hline \multirow{3}{*}{ LA } & Grade 1 & 3800 & 3.3979 & 0.78195 & \multirow{3}{*}{36.502} & \multirow{3}{*}{.000} \\
\hline & Grade 2 & 1930 & 3.5969 & 0.98745 & & \\
\hline & Grade 3 & 596 & 3.5151 & 0.71463 & & \\
\hline \multirow{3}{*}{ SE } & Grade 1 & 3782 & 3.5701 & 0.66464 & \multirow{3}{*}{6.211} & \multirow{3}{*}{$\begin{array}{c}.00 \\
2\end{array}$} \\
\hline & Grade 2 & 1927 & 3.6338 & 0.70179 & & \\
\hline & Grade 3 & 598 & 3.621 & 0.64665 & & \\
\hline \multirow{3}{*}{ LMA } & Grade 1 & 3782 & 3.5025 & 0.76093 & \multirow{3}{*}{11.729} & \multirow{3}{*}{.000} \\
\hline & Grade 2 & 1920 & 3.6049 & 0.71375 & & \\
\hline & Grade 3 & 596 & 3.578 & 1.0553 & & \\
\hline
\end{tabular}

\section{The college type differences}

As demonstrated in Table IV, the one-way ANOVA analysis result showed that, the college type differences of factors including $\operatorname{ILM}(\mathrm{Sig}=.000), \quad \mathrm{EF}(\mathrm{Sig}=.027)$, $\mathrm{LM}($ Sig=.000), LC(Sig=.000), SE(Sig=.000) were significant, while the college type differences of factor IPC (Sig=.120), LS (Sig=.965) , LA(Sig=.115), LMA(.Sig=.936) were no significant. The factors' level of public colleges included ILM, EF, LM, LC, SE were significantly higher than those of private colleges. And factors' level of public colleges included IPC,LS were slightly higher than those of private colleges. Meanwhile, the level of factor LA of private colleges was higher than that of public colleges. Overall, public college students thought that their levels of Web-based autonomous learning ability including information processing ability, intrinsic learning motivation, self-efficacy, learning meaning, learning control and their learning environment ware better than that of private college students. In addition, private college students' anxiety level is higher than that of students in public college. According to the data, private college students need more supports when they learning online autonomously. 
TABLE IV. THE COLlege TyPE DifFERENCES

\begin{tabular}{|c|c|c|c|c|c|c|}
\hline \multicolumn{2}{|c|}{ Factor } & $\mathbf{N}$ & Mean & SD & $\mathbf{F}$ & Sig \\
\hline \multirow{2}{*}{ IPC } & Public & 4862 & 3.5216 & 0.62956 & \multirow{2}{*}{2.417} & \multirow{2}{*}{. 120} \\
\hline & Private & 1463 & 3.4921 & 0.65925 & & \\
\hline \multirow{2}{*}{ ILM } & Public & 4886 & 3.6205 & 0.68896 & \multirow[b]{2}{*}{62.475} & \multirow[b]{2}{*}{.000} \\
\hline & Private & 1473 & 3.4596 & 0.67178 & & \\
\hline \multirow{2}{*}{ LS } & Public & 4823 & 3.5715 & 0.62065 & \multirow[b]{2}{*}{.002} & \multirow[b]{2}{*}{.965 } \\
\hline & Private & 1447 & 3.5707 & 0.58029 & & \\
\hline \multirow{2}{*}{$\mathrm{EF}$} & Public & 4865 & 3.6273 & 0.63725 & \multirow[b]{2}{*}{4.909} & \multirow{2}{*}{.027} \\
\hline & Private & 1461 & 3.5852 & 0.63402 & & \\
\hline \multirow{2}{*}{ LM } & Public & 4826 & 3.6448 & 0.7126 & \multirow[b]{2}{*}{20.548} & \multirow[b]{2}{*}{.000} \\
\hline & Private & 1453 & 3.5462 & 0.77294 & & \\
\hline \multirow{2}{*}{ LC } & Public & 4882 & 3.1184 & 0.72422 & \multirow{2}{*}{28.781} & \multirow[b]{2}{*}{.000 } \\
\hline & Private & 1477 & 3.0085 & 0.56228 & & \\
\hline \multirow{2}{*}{ LA } & Public & 4876 & 3.4574 & 0.88253 & \multirow[b]{2}{*}{2.487} & \multirow{2}{*}{. 115} \\
\hline & Private & 1470 & 3.4973 & 0.72633 & & \\
\hline \multirow{2}{*}{ SE } & Public & 4861 & 3.6098 & 0.67626 & \multirow[b]{2}{*}{18.612} & \multirow[b]{2}{*}{.000} \\
\hline & Private & 1468 & 3.5229 & 0.67626 & & \\
\hline \multirow{2}{*}{ LMA } & Public & 4850 & 3.5373 & 0.75516 & \multirow[b]{2}{*}{.006} & \multirow[b]{2}{*}{.936} \\
\hline & Private & 1467 & 3.5392 & 0.86563 & & \\
\hline
\end{tabular}

\section{E. The Environmental factors}

The author analyzed four aspects of the exterior environmental factors of learners so as to gain insight into the impact of environmental factors on Web-based autonomous learning. The item 'Learning devices \& tools(LDT)'concerned about whether the students' intelligent mobile phone, tablet computer, notebook and other tools used can meet the need of online learning; the item 'Network access condition (NAC)' concerned about whether students can easily access network via wired or wireless network both at school and at home; the item 'Procurability \& convenience of online learning resources (PCR)' concerned about whether students can easily find their professional learning resources in need(including learning tools, online-courses, micro lectures etc.) ; the item 'Learning supports from Teachers (LST) 'concerned about whether students often communicate with teachers about online learning or get support from them. Data analysis revealed that the scores of four items as LDT(Mean=3.78) > NAC $($ Mean=3.71) > PCR(Mean=3.64) > LST(Mean=3.33), showed that students received the support from teachers with the lowest score.

The result of Bivariate Correlation analysis demonstrated in Table V, the four aspects of environmental factors(LDT, NAC, PCR, LST) and internal factors of learners (Intrinsic learning motivation, Learning strategies, Learning meaning, Learning control, Learning anxiety, Self-efficacy and Learning management) were positively related.
TABLE V. PEARSON CORRELATION BETWEEN EXTERIOR ENVIRONMENTAL FACTORS \& INTERIOR FACTORS

\begin{tabular}{|c|c|c|c|c|c|c|c|}
\hline $\begin{array}{c}\text { Environmental } \\
\text { Factor } \\
\end{array}$ & ILM & LS & LM & LC & LA & $\overline{S E}$ & LMA \\
\hline $\begin{array}{l}\text { Learning } \\
\text { devices \& } \\
\text { tools(LDT) }\end{array}$ & $.259 * *$ & $.266^{* *}$ & $.260 * *$ & $.057 * *$ & $.136^{* *}$ & $.254 * *$ & $.226 * *$ \\
\hline $\begin{array}{l}\text { Network access } \\
\text { condition(NAC) }\end{array}$ & $.296 * *$ & $.323^{* *}$ & $.325^{* * *}$ & $.096 * *$ & $.164^{* *}$ & $.315^{* *}$ & $.248 * *$ \\
\hline $\begin{array}{l}\text { Procurability \& } \\
\text { convenience of } \\
\text { online learning } \\
\text { resources(PCR) }\end{array}$ & $.298 * *$ & $.363 * *$ & $.343 * *$ & $.104 * *$ & $.144^{* *}$ & $.373 * *$ & $.289 * *$ \\
\hline $\begin{array}{l}\text { Learning } \\
\text { supports from } \\
\text { Teachers(LST) }\end{array}$ & $.246^{* *}$ & $.448 * *$ & $.283^{* * *}$ & $.099 * *$ & $.287 * *$ & $.362 * *$ & $.376^{* *}$ \\
\hline
\end{tabular}

**. Correlation is significant at the 0.01 level (2-tailed)

\section{DISCUSSION AND CONCLUSIONS}

The result showed that boys were better adapted to Webbased autonomous learning than girls; data showed that except for factor Intrinsic learning motivation, the other factors' score of boys were all higher than those of girls. We should pay attention to gender differences in fostering the ability of Webbased autonomous learning, and give more support to girls. Improving the evaluation method course model of online learning would be helpful for improving the learning motivation of boys, and girls should be given more supports when they participated in online learning.

Students' information processing capacity was continually grown while the students' intrinsic learning motivation of Web-based autonomous learning was decreased gradually in 3 Years. The scores of factors included LS, EF, LM, LC, LA, SE, LMA all showed rise first and then decrease slightly, revealed that there was a peak in grade2. Teachers of vocational colleges should combine students' the requirements of employment with the procedure of fostering the Web-based autonomous learning ability. We should improve the students' ability of information processing and promote their awareness of lifelong learning with information technology, especially in the teaching of specialized courses.

The Web-based autonomous learning ability of students in public colleges was superior to those in private colleges. The factors of public student including Information processing ability, Intrinsic learning motivation, Self-efficacy, Learning meaning, Learning control and their learning environment ware better than that of private college students. The private colleges should take efforts to improve their students' ability to process information, and strengthen students' learning goals with professional education courses, help their students to understand the learning meaning by set up reasonable and achievable learning goals to make progresses. Apply the computer-supported cooperative learning, project-based, outcome-oriented method to encourage the participation of students, imply the e-portfolios of work as assessment method to establish students' self-confidence of learning tasks, so as to enhance their sense of self-efficacy. 
Improving students' online learning environment factors is of great significance for fostering the ability. The result revealed that the four aspects of environmental factors (LDT, NAC, PCR and LST) and internal factors of learners are positively related, and the support from teachers was insufficient. If the college and the parents of students pay more fund and attention to improve students' exterior learning environment, including provide convenient conditions for the network access, give them necessary and high performed devices and learning tools, offer them more available and welldesigned learning resources, the students would also improve their participation and self-efficacy of Web-based autonomous learning activities in higher vocational education.

\section{ACKNOWLEDGMENT}

This study was supported by the Cultivation Project for Excellent Young Teacher in Guangdong Universities (Grant \# YQ2015175 in 2015), Research Project of Educational Technology Reform in Higher Education Institutions of Guangdong Province (Grant \# 2015086 in 2015) , Guangdong University Student Scientific and Technological Innovation Cultivation Project (Grant \# pdjh2016a0562 in 2016), Funded Project for research teams of Guangdong Teachers College of
Foreign Language and Arts(Grant \# 2014KYTD01 in 2014). We want to thank all the participants in this study for their cooperation.

\section{REFERENCES}

[1] People's Daily Online.Retrieved May 05,2017,from http://society.people.com.cn/n/2015/0611/c136657-27136006.html.

[2] Desmond Keegan.(1999).Theoretical Principles of Distance Education. Beijing:The Central Radio and TV University Press, pp. 68-73(In Chinese).

[3] Zhai Xuge. The Researeh on factors influencing Self-regulated Elearning of College Students (Masteral dissertation, Dalian University of Technology,2008).

[4] Li Xingrong, Guo Hongsheng ,et al.(2009).An Empirical Analysis of the Factors Affecting the Results of College Students' Web-based Autonomous Learning, Modern Education Management,(9), pp. 5760(In Chinese).

[5] Li Chengxin.(2009).An investigation on web-based autonomous learning of college students(Masteral dissertation, Dalian University of Technology,2009).

[6] Yi Ya-nan.(2012) The Research on Factors Influencing Web-based Autonomous Learning of College Students(Masteral dissertation, Qiqihar University,2012). 